Original Article

\title{
Changes in cervical muscle activity according to the traction force of an air-inflatable neck traction device
}

\author{
Jong Ho Kang, PT, $\mathrm{PhD}^{1)}$, TAe-Sung ParK ${ }^{1)^{*}}$ \\ 1) Department of Physical Therapy, College of Health Sciences, Catholic University of Pusan: \\ 57 Oryundae-ro, Geumjeong-gu, Busan 609-757, Republic of Korea
}

\begin{abstract}
Purpose] The purpose of this study was to analyze cervical muscle activity at different traction forces of an air-inflatable neck traction device. [Subjects] Eighteen males participated in this study. [Methods] The subjects put on an air-inflatable neck traction device and the traction forces administered were 40,80 , and $120 \mathrm{mmHg}$. The electromyography (EMG) signals of the splenius capitis, and upper trapezius were measured to assess the muscle activity. [Results] The muscle activity of the splenius capitis was significantly higher at 80 , and $120 \mathrm{mmHg}$ compared to $40 \mathrm{mmHg}$. The muscle activity of the upper trapezius did not show significant differences among the traction forces. [Conclusion] Our research result showed that the air-inflatable home neck traction device did not meet the condition of muscle relaxation.

Key words: Air-inflatable neck traction device, Electromyography, Muscle relaxation
\end{abstract}

(This article was submitted Apr. 16, 2015, and was accepted May 25, 2015)

\section{INTRODUCTION}

The generally known traction effect of traditional-style home neck traction devices has been supported by scientific evidence. The most representative home traction device are over-the-door traction devices, which are connected to sandbags or water bags with ropes. They are similar to the standard neck traction device used in hospitals. These device may include an adjustable traction position and angle ${ }^{1)}$. Other types of home neck traction device are products that are ergonomically designed in relation to traction position and traction angle, and their sufficient traction effect has been proven $^{2)}$. This include air-inflatable neck traction devices, which are economical, light, and easily wearable compared to other traction devices; therefore, they have attracted the attention clinicians and patients. However, according to some investigations, the traction effect of air-inflatable neck traction devices has not been properly verified relative to other home traction devices.

Previous studies have verified the traction effect by analyzing radiological images ${ }^{2)}$ or evaluating the activity ${ }^{3)}$ or thickness of the muscles ${ }^{4}$ ) around the vertebrae during traction. Once traction force is provided, the space between the vertebrae will be enhanced ${ }^{5)}$. However, if muscular contraction increases during traction, elongation between the vertebrae may be interrupted, and discomfort may be trig-

\section{*Corresponding author. Tae-Sung Park (E-mail: tsbark@} naver.com)

C2015 The Society of Physical Therapy Science. Published by IPEC Inc. This is an open-access article distributed under the terms of the Creative Commons Attribution Non-Commercial No Derivatives (by-ncnd) License $<$ http://creativecommons.org/licenses/by-nc-nd/3.0/> . gered in the subjects, therby offsetting the traction effects ${ }^{6}$. This study aims to examine the effects of air-inflatable neck traction devices, which have not yet been sufficiently verified. To this end, this study investigated the use of different traction forces of an air-inflatable neck traction device and the activity of the muscles around the neck was observed.

\section{SUBJECTS AND METHODS}

The subjects who participated in this study were 18 healthy adult males without orthopedic disease of the neck or shoulders (age, 22.3 \pm 1.8 years; height, $175.5 \pm 4.2 \mathrm{~cm}$; weight, $71.3 \pm 6.2 \mathrm{~kg}$ ). According to the ethical standards of the Declaration of Helsinki, the study purpose, content, and procedure were explained to all subjects in detail, and only those who voluntarily signed an informed consent participated in the experiment. Moreover, the study was approved by the institutional review board of the Catholic University of Pusan. For neck traction, an air-inflatable neck traction device (Diskwell, Eunsung Inc., Korea) was used and a mercury manometer (CK-101, Sprit Inc., Taiwan) was connected to the traction device for remodeling so that the traction force could be measured. Cervical traction was conducted in a sitting position, as generally done in a hospital. The height of the chair used was adjustable, and it was an armchair with a back. The height of the chair was adjusted so that the ankle, knee, and hip joints reached 90 degrees and the trunk and the arms were supported by the back and arm of the chair. Through these measures, the contraction of the muscles around the neck resulting from movement of the trunk and arms was controlled.

First, in a sitting position, the subjects put on a neck traction device and rested for 1 minute, looking straight and sitting comfortably. The traction forces provided to 
the subjects were 40,80 , and $120 \mathrm{mmHg}$, and each force was administered for 30 seconds. The pressure were employed in a random order. When air was injected, the neck traction device inflated, with the neck posture in a natural state. Previous studies that evaluated the effects of a traction device measured the activity of the muscles around the neck to verify the traction effects and experimented on the appropriateness of ergonomic traction devices using electromyography $(\mathrm{EMG})^{3)}$.

Accordingly, this study measured the activity of the muscles around the neck while applying traction with an air-inflatable neck traction device using an EMG system (LXM-3204, LAXTHA Inc., Korea). The sampling frequency was set at $1,000 \mathrm{~Hz}$ and the obtained EMG signals were processed with a $60 \mathrm{~Hz}$ notch filter and a $50-500 \mathrm{~Hz}$ bandpass filter. The muscles used for the muscle activity analysis were the splenius capitis and upper trapezius ${ }^{4)}$. The subjects were placed in a prone position at the corner of a bed, a $2 \mathrm{~kg}$ sandbag was placed behind their head, and the head was extended. EMG signals were collected for $20 \mathrm{sec}-$ onds, and signals for 10 seconds excluding the first and last 5 seconds were collected and used as a reference for voluntary contraction of the splenius capitis. In an anatomical position, the subjects grasped a $1 \mathrm{~kg}$ dumbbell, abducted both arms by 90 degrees and contracted them for 20 seconds. Signals for 10 seconds excluding the first and the last 5 seconds were collected and used as a reference for voluntary contraction of the upper trapezius. Before and after neck traction with air pressures of 40, 80, and $120 \mathrm{mmHg}$, the EMG signals of the splenius capitis and upper trapezius were collected for 30 seconds. Signals for 20 seconds excluding the first and the last 5 seconds were collected, and the \% reference voluntary contraction (RVC) was derived using each muscle's RVC value. Data obtained while conducting the experiment were expressed as average and standard deviation. In order to compare the EMG values before and during the application of each traction force, a Wilcoxon signed-rank test was conducted, and the significance level was set at 0.05 .

\section{RESULTS}

The muscle activity of the splenius capitis was $33.1 \pm 2.9$ prior to the application of traction force and $34.5 \pm 2.6$ $36.9 \pm 2.5$, and $40.9 \pm 4.3$ with traction forces of 40,80 , and $120 \mathrm{mmHg}$, respectively. While each traction force was applied, muscle activity increased with statistically significant differences. The muscle activity of the upper trapezius was $7.0 \pm 0.9$ before the traction force was applied and $7.0 \pm 0.9$, $7.0 \pm 0.8$, and $6.9 \pm 0.8$ with traction forces of 40,80 , and $120 \mathrm{mmHg}$, respectively; no statistically difference was observed.

\section{DISCUSSION}

The important mechanism of traction is an increase in the intervertebral space through spinal elongation and muscle relaxation ${ }^{6}$. Our study examined changes in muscle activity during traction using EMG. The results showed that when a low traction force of $40 \mathrm{mmHg}$ was provided with an air-inflatable home neck traction device, the splenius capitis contracted significantly. Then, when traction forces of a middle intensity of $80 \mathrm{mmHg}$ and a high intensity of $120 \mathrm{mmHg}$ were administered, a greater contraction was observed. Muscle contraction, which occurs during cervical traction, has an important significance. In general, when cervical radiculopathy is caused by a herniated nucleus pulposus, the herniated disk compresses the nerve roots, resulting in an entrapment of the intervertebral foramina. As a result, the nerves are irritated and the reflex response of the cervical muscles may trigger muscle contraction and resulting neck pain. The contracted muscles increase pressure on the intervertebral discs and compression on the nerve roots, which may aid in creating a vicious cycle of aggravating pain ${ }^{7,8}$. In addition, the splenius capitis, whose contraction increased in the present study, is known as a muscle that triggers occipital neuralgia ${ }^{9}$.

Murphy $^{3)}$ noted that the simultaneous realization of an increase in intervertebral space through spinal elongation and muscle relaxation might interrupt the cycle of neck pain. From this perspective, it can be stated that when a vertical traction force is provided, spinal elongation may naturally occur; however, the accompaniment of muscle contraction during this process may offset the traction effect.

Recently, Katsushi $\left.{ }^{4}\right)$ proposed that a traction force of a low intensity, such as $5 \mathrm{~kg}$ or $8 \mathrm{~kg}$, did not significantly change the thickness of the upper trapezius; however he reported that a traction force of a high intensity at $11 \mathrm{~kg}$ might significantly decrease muscle thickness. In other words, when a relatively high traction force is given, changes in the upper trapezius may be triggered. However, this study showed no differences in the activity of the upper trapezius. In particular, the muscle activity did not differ at 40,80 , or $120 \mathrm{mmHg}$. Thus the air-inflatable neck traction device is not considered to provide stimulation to the upper trapezius.

Katsushi ${ }^{4}$ administered intermittent cervical traction in a reclining wheelchair composed of traction for 20 seconds and resting for 10 seconds with the cervical flexion angle at 10 degrees; meanwhile, we used the same sitting posture as that in a hospital but traction device's cervical flexion angle was uncontrollable. Therefore, the differences between the two studies's results are considered to have emerged from differences in the traction positions, cervical flexion angles, or types of traction devices. According to the results of increasing the air pressure of the traction device and monitoring the subjects' responses, as the volume of the traction device increased with rising air pressure, the chins of the subjects were raised and their necks were extended backwards. This is considered to occur because of the structure of the airinflatable cervical traction device. In general, it is known that cervical traction is effective when performing traction in a posture of flexion of 20 to 30 degrees $^{10)}$. In contrast, the posture of neck extension may fail to generate spinal elongation, and instead narrow the intervertebral space ${ }^{5)}$; when this is narrowed, compression on the nerve roots may increase, triggering a contraction of the muscles around the neck ${ }^{3)}$. Therefore, increased muscle activity of the splenius capitis in this study is estimated to be the problem with the structure of the air-inflatable home traction device, which extends the neck as the air pressure rises.

The air-inflatable neck disk traction device is a traction 
unit used in a sitting posture, and muscle activity is regarded as differing according to traction posture. Katsushi ${ }^{4}$ ) minimized the contraction of the muscles around the neck during traction by positioning the head of the subject on the headrest in a reclining wheelchair. Moreover, Jette et al. ${ }^{11)}$ had their subjects rest for 5 minutes prior to traction, thereby reducing the influence of gravity on the muscles. When traction is conducted in a sitting posture, the subject is influenced by gravity and therefore muscle activity increases more than when traction is performed in a lying position or supporting the head. Fater and Kernozek ${ }^{12)}$ noted that the space between intervertebral bodies increased more in a lying position than in a sitting position, while Murphy ${ }^{3}$ observed that muscle activity around the neck increased more in a sitting position than in a lying posture. According to previous studies, it has been demonstrated that muscle activity is higher in a sitting position than in a lying position. In the present study, the activity of the splenius capitis increased as well, and this is explained in that the posture of traction conducted in a sitting position is a major factor.

The results of this study show that the indiscriminate use of an air-inflatable home neck traction device may aggravate symptoms. The structure of the device, method of applying traction, and the traction posture are all considered to have an effect. Therefore, these elements should be considered as independent variables in a more detailed analysis of the appropriate structure, posture, and utilization method related to air-inflatable home neck traction devices.

\section{ACKNOWLEDGEMENT}

This paper was supported by research funds provided by the Catholic University of Pusan.

\section{REFERENCES}

1) Cai C, Ming G, Ng LY: Development of a clinical prediction rule to identify patients with neck pain who are likely to benefit from home-based mechanical cervical traction. Eur Spine J, 2011, 20: 912-922. [Medline] [CrossRef]

2) Chung TS, Lee YJ, Kang SW, et al.: Reducibility of cervical disk herniation: evaluation at MR imaging during cervical traction with a nonmagnetic traction device. Radiology, 2002, 225: 895-900. [Medline] [CrossRef]

3) Murphy MJ: Effects of cervical traction on muscle activity. J Orthop Sports Phys Ther, 1991, 13: 220-225. [Medline] [CrossRef]

4) Kuniyasu K: Changes in neck muscle thickness due to differences in intermittent cervical traction force measured by ultrasonography. J Phys Ther Sci, 2014, 26: 785-787. [Medline] [CrossRef]

5) Wong AM, Leong CP, Chen CM: The traction angle and cervical intervertebral separation. Spine, 1992, 17: 136-138. [Medline] [CrossRef]

6) Atteya AA: Biofeedback traction versus conventional traction in cervical radiculopathy. Neurosci Riyadh, 2004, 9: 91-93. [Medline]

7) Andersson GB, Schultz AB, Nachemson AL: Intervertebral disc pressures during traction. Scand J Rehabil Med Suppl, 1983, 9: 88-91. [Medline]

8) Kim JS: The study about the effect of chiropractic physical therapy on patients with cervical hypolordosis. Myongji University, PhD dissertation, 2006.

9) Son BC, Kim DR, Lee SW: Intractable occipital neuralgia caused by an entrapment in the semispinalis capitis. J Korean Neurosurg Soc, 2013, 54: 268-271. [Medline] [CrossRef]

10) Raney NH, Petersen EJ, Smith TA, et al.: Development of a clinical prediction rule to identify patients with neck pain likely to benefit from cervical traction and exercise. Eur Spine J, 2009, 18: 382-391. [Medline] [CrossRef]

11) Jette DU, Falkel JE, Trombly C: Effect of intermittent, supine cervical traction on the myoelectric activity of the upper trapezius muscle in subjects with neck pain. Phys Ther, 1985, 65: 1173-1176. [Medline]

12) Fater DC, Kernozek TW: Comparison of cervical vertebral separation in the supine and seated positions using home traction units. Physiother Theory Pract, 2008, 24: 430-436. [Medline] [CrossRef] 